\title{
Bolos sem glúten a base de arroz quebrado e casca de mandioca
}

\section{Gluten free cakes made with broken rice and cassava peel}

\author{
Thaísa Anders Carvalho Souza ${ }^{1 *}$; Manoel Soares Soares Júnior ${ }^{2}$; \\ Maria Raquel Hidalgo Campos²; Thaynara Stella Carvalho Souza'; \\ Tiago Dias ${ }^{3}$; Fernanda Assumpção Fiorda ${ }^{1}$
}

\section{Resumo}

As agroindústrias de arroz e de mandioca geram significativos volumes de grãos quebrados (subprodutos) e cascas (resíduos). O descarte indevido dos resíduos constitui desperdício de matéria-prima, que poderia ser aproveitada melhor, em função do grande montante produzido e de seu valor nutricional. O objetivo deste trabalho foi verificar a viabilidade da aplicação de casca de mandioca desidratada na formulação de misturas de bolos sem glúten em substituição a farinha de arroz. Os bolos foram formulados com diferentes níveis de substituição da farinha de arroz (FA) pela farinha da casca de mandioca (FCM) $(0 \%, 25 \%, 50 \%, 75 \%$ e $100 \%)$, com base em volume. Para obtenção da farinha, a casca de mandioca foi desidratada e moída. As amostras de farinhas e bolos foram submetidas a análises físicas, de composição centesimal, e microbiológicas (Bacilus cereus, coliformes totais e a $45^{\circ} \mathrm{C}$, Salmonella $\mathrm{sp}$, bolores e leveduras e clostrídios sulfitos redutores) e aceitação sensorial. Os bolos diferiram $(p \leq 0,05)$ no teor de umidade $\left(29,6\right.$ a 41,8 g. $\left.100 \mathrm{~g}^{-1}\right)$, que foi maior com o aumento da proporção da FCM. A mesma tendência foi observada no coeficiente de índice de rendimento $(0,72$ a 0,84$)$, e nos teores de cinzas $(3,1$ a 4,8 g.100g-1 $)$, lipídeos $\left(8,6-16,7\right.$ g.100 g- $\left.{ }^{-1}\right)$ e fibra alimentar total $\left(4,1\right.$ a 19,3 g. $\left.100 \mathrm{~g}^{-1}\right)$ e insolúvel $(3,5$ a 17,3 g. $\left.100 \mathrm{~g}^{-1}\right)$. Os bolos não apresentaram contaminação microbiológica. Em relação aos atributos sensoriais, os bolos tiveram a mesma aceitação (em torno de 6,8), e a maior intenção de compra (40\%) foi obtida pela amostra com $100 \%$ de substituição de FA por FCM. Os resultados permitem inferir que existe possibilidade da utilização da farinha de casca de mandioca como substituinte da farinha de arroz em formulações de bolos sem glúten em até $100 \%$ de substituição, uma vez que, as características nutricionais, microbiológicas e a aceitação sensorial foram satisfatórias.

Palavras-chave: Oriyza sativa L., Manihot esculenta Crantz, subproduto, resíduo, desenvolvimento de produtos

\begin{abstract}
The agribusiness rice and cassava generate significant volumes of broken grains (byproducts) and bark (waste). The improper disposal of waste is waste of cassava feedstock, which could be better utilized, due to the large amount produced and its nutritional value. The objective of this study was to investigate the feasibility of applying dried cassava peel in the formulation of mixtures of gluten free cakes instead of rice flour. The cakes were formulated with different substitution levels of rice flour (RF) by peeling cassava flour (PCF) $(0 \%, 25 \%, 50 \%, 75 \%$ and $100 \%)$, based on volume. To obtain the flour, cassava hull was dehydrated and milled. Samples of flour and cakes were submitted to physical, proximate composition, and microbiological analysis (Bacillus cereus, total coliforms at $45{ }^{\circ} \mathrm{C}$, Salmonella, mold and yeast and sulfites reducing clostridia) and sensory acceptance. The cakes differ $(\mathrm{p} \leq 0.05)$ in

\footnotetext{
${ }^{1}$ Discente(s), Universidade Federal de Goiás, UFG, Goiânia, GO. E-mail: thaisanut@yahoo.com.br; thaynarastella@gmail.com; fernandafiorda@hotmail.com

${ }^{2}$ Profs. Drs., UFG, Goiânia, GO.E-mail: mssoaresjr@hotmail.com; raq7@brturbo.com.br

${ }^{3}$ Pesquisador da UFG, Goiânia, GO. E-mail: tiagodias@fanut.ufg.br

* Autor para correspondência
} 
moisture content (29,6 to $\left.41,8 \mathrm{~g} \cdot 100 \mathrm{~g}^{-1}\right)$, with a tendency to increase with the level of substitution of rice flour by flour cassava peel , the same trend was observed in the coefficient of performance index $(0,72$ to 0,84$)$ and the contents of ash $\left(3,1\right.$ to 4,8 g. $\left.100 \mathrm{~g}^{-1}\right)$, lipids $\left(8,6\right.$ to $\left.16,7 \mathrm{~g} \cdot 100 \mathrm{~g}^{-1}\right)$ and total $(4,1$ to 19,3 g. $\left.100 \mathrm{~g}^{-1}\right)$ and insoluble dietary fibers $\left(3,5\right.$ to $\left.17,3 \mathrm{~g} \cdot 100 \mathrm{~g}^{-1}\right)$. No contamination by microorganisms was observed. Regarding sensory attributes, all samples were accepted (around 6,8), and the higher purchase intent $(40 \%)$ was obtained for the sample with $100 \%$ replacement of RF by PCF. The results allow to point that there is possibility of using cassava peel meal substituted rice flour for gluten-free cakes formulations up to $100 \%$ of substitution, since the nutritional, microbiological properties and sensory acceptance were satisfactory.

Key words: Oriyza sativa L., Manihot esculenta Crantz, byproducts, residue, product development

\section{Introdução}

O arroz (Oriza sativa L.) é um cereal rico em amido, e um dos principais alimentos em muitas partes do mundo. Uma parte da produção é beneficiada, dando origem a um resíduo denominado "arroz quebrado", o que gera considerável perda de rendimento na produção do grão polido, principal forma consumida no Brasil. Esse subproduto vem sendo transformado em farinha de arroz, que pode substituir parcial ou totalmente a farinha de trigo, em diversos alimentos, como nos produtos de panificação, de confeitaria e de conveniência, além se ser utilizado na elaboração de extratos vegetais ou servir como base para novos ingredientes, como farinhas mistas e amidos modificados (CARVALHO et al., 2011; SOARES JÚNIOR et al., 2010; SOARES JÚNIOR et al., 2011; TAVARES et al., 2012).

Um possível público para o consumo de produtos elaborados com a farinha de arroz são os portadores de doença celíaca, que precisam excluir a farinha de trigo e seus derivados da dieta. É fundamental para o doente o cumprimento efetivo de uma dieta sem glúten, a fim de assegurar desenvolvimento pônderoestatural e puberal adequados, densidade mineral óssea, fertilidade, redução de risco de deficiência de macro e micronutrientes, assim como a diminuição do risco do surgimento de doenças, particularmente do sistema digestivo (SDEPANIAN; MORAIS; FAGUNDES-NETO, 2001).

Outra opção para os portadores de doença celíaca são os produtos derivados da mandioca. Originária da América do Sul, a raiz da mandioca (Manihot esculenta Crantz) é um dos principais alimentos para cerca de 700 milhões de pessoas, mais de 80 países são produtores desta raiz, sendo o Brasil um dos maiores do mundo (EMBRAPA, 2009). A produção industrial da mandioca, principalmente de fécula e farinha, gera significativo volume de resíduos, que podem causar sérios problemas ambientais. Além deste aspecto de agressão ao meio ambiente, o descarte indevido dos resíduos da mandioca constitui desperdício de matéria-prima, que poderia ser aproveitada melhor, em função do grande montante produzido e de seu valor nutricional (CEREDA, 1994). Entre os resíduos sólidos das indústrias extratoras de amido de mandioca esta a casca. Esta é composta pelas frações denominadas de casca marrom e de entrecasca. Para adequar-se à visão industrial, a mistura das frações é simplesmente expressa como casca (CEREDA, 2002).

Para produção de uma tonelada de amido de mandioca são produzidos $428 \mathrm{~kg}$ de casca com $80 \%$ de umidade, correspondente a $85 \mathrm{~kg}$ de material seco (CEREDA, 1994). As demandas da indústria e dos órgãos ambientais têm despertado interesse sobre o aproveitamento de resíduos, propiciando o surgimento de pesquisas para viabilizar a utilização destes resíduos na área agronômica (adubação, produção de compostagem, cultivo de cogumelos). Pesquisas comprovam os bons resultados do cultivo de shitake em substrato constituído de bagaço e de cascas de mandioca (VILPOUX, 2003).

Um estudo recente apontou a possibilidade do aproveitamento da farinha de casca de mandioca na 
alimentação humana. Pelo fato de ser desperdiçada grande quantidade de entrecasca e de casca marrom, que possuem amido e fibra alimentar insolúvel, o resíduo "casca" apresenta interesse do ponto de vista nutricional e pela maior valorização do consumo de fibras na prevenção de doenças crônicas, podendo ser também utilizado na elaboração de pão de forma (VILHALVA et al., 2011, 2012; BRITO, 2008).

A aplicação da casca de mandioca na alimentação humana requer cuidado pela presença de cianetos. Entretanto, por ser solúvel em água, a maior parte dos glicosídeos capazes de gerar ácido cianídrico (HCN) é removida durante o processamento. A redução efetiva do nível de compostos cianogênicos requer duas fases: primeiro a ralação ou trituração das raízes, e segundo, o aquecimento da massa de raízes raladas para remover os resíduos de cianeto livre (CAGNON; CEREDA; PANTAROTTO, 2002). Assim, na elaboração de uma farinha de casca de mandioca, onde são utilizados os dois métodos para eliminação dos compostos cianogênicos, a segurança do produto pode ser garantida. Portanto, a casca de mandioca pode também encontrar aplicações tanto para a alimentação humana como animal.

Com o aumento da industrialização e, consequentemente, na produção de resíduos, as legislações de gestão de resíduos estão sendo reforçadas, existindo uma necessidade real das agroindústrias em desenvolver alternativas e métodos eficientes para destinação ou utilização destes resíduos (UGWU; TOKIWA; AOYAGI, 2012). Por outro lado, as necessidades econômicas atuais têm levado as indústrias a revisarem seus processos e a qualidade dos seus produtos. Assim, as empresas de amido de mandioca vêem a necessidade de buscar novos mercados para seu produto, bem como formas de agregar valor aos seus resíduos, através de tecnologias de baixo custo de implantação (CAMARGO; LEONEL; MISCHAN, 2008). Para que a casca gerada a partir da industrialização da fécula de mandioca seja rentável é importante desenvolver alternativas para o aproveitamento deste material. Assim, o objetivo deste trabalho foi obter a farinha de casca de mandioca e verificar a viabilidade da sua aplicação na alimentação humana, por meio do desenvolvimento de bolos, em substituição à farinha de arroz.

\section{Material e Métodos}

\section{Material}

A casca de mandioca, da cultivar IAC-12, safra 2009/2010, foi doada pela Fecularia Bela Vista Febela Ltda., situada em Bela Vista de Goiás, Goiás, Brasil. As amostras foram coletadas na saída da área de lavagem e descascamento, utilizando-se sacos de polietileno de baixa densidade Bioline ${ }^{\circledR}$. Após a coleta, as amostras foram colocadas em caixa isotérmica com gelo mineral, visando manutenção da temperatura de $0{ }^{\circ} \mathrm{C}$ durante o transporte. Os grãos quebrados de arroz utilizados para a produção da farinha (FA) foram doados pela Empresa Arroz Cristal, de Aparecida de Goiânia - GO. Os demais ingredientes utilizados na formulação dos bolos foram adquiridos no comércio local.

Processamento das farinhas de arroz e de casca de mandioca

$\mathrm{O}$ arroz quebrado foi submetido a moagem em moinho de facas (Marconi, MA-090 CET, Piracicaba-SP, Brasil), com peneira de 30 mesh para padronização do tamanho das partículas, originando a farinha de arroz (FA). A casca de mandioca foi imersa em solução de hipoclorito de sódio-Cromoline ${ }^{\circledR}$, na concentração de $200 \mathrm{ppm}$ por $15 \mathrm{~min}$ (valores confirmados com fitas de cloro-teste-Hidroall®), visando redução da carga microbiana. Em seguida, a casca de mandioca foi seca em estufa com circulação forçada de ar (Tecnal, TE394/3, Piracicaba-SP, Brasil), em temperatura de $57^{\circ} \mathrm{C}$, até atingir $14 \%$ de umidade $( \pm 1 \%)$. Após a secagem o resíduo passou por moinho nas mesmas condições e equipamento utilizado para o processamento da FA, para obtenção da farinha de casca de mandioca (FCM). 
Formulação e processamento dos bolos

Os bolos foram formulados com diferentes níveis de substituição $(0 \%, 25 \%, 50 \%, 75 \%$ e $100 \%$ ) de FA por FCM, com base em volume (v/v), conforme apresentado na Tabela 1. A quantidade de água utilizada em cada formulação foi diferente e proporcional a capacidade de absorção de água pela mistura de farinhas de arroz e de casca de mandioca, sendo suficiente para homogeneização e manutenção da mesma viscosidade entre as massas cruas.

Tabela 1. Formulação dos bolos experimentais em função dos níveis de substituição da farinha de trigo por farinha da casca de mandioca.

\section{Tratamento}

Ingrediente (Nível de substituição da farinha de trigo por farinha da casca de mandioca)

\begin{tabular}{lrrrrr} 
& $\mathrm{B} 1(0 \%)$ & $\mathrm{B} 2(25 \%)$ & $\mathrm{B} 3(50 \%)$ & $\mathrm{B} 4(75 \%)$ & $\mathrm{B} 5(100 \%)$ \\
\hline Açúcar cristal $(\mathrm{g})$ & 109,5 & 109,5 & 109,5 & 109,5 & 109,5 \\
Leite pasteurizado integral $(\mathrm{mL})$ & 98 & 98 & 98 & 98 & 98 \\
Margarina vegetal sem sal $(\mathrm{g})$ & 48,5 & 48,5 & 48,5 & 48,5 & 48,5 \\
Fermento químico em pó $(\mathrm{g})$ & 13,5 & 13,5 & 13,5 & 13,5 & 13,5 \\
Ovo $(\mathrm{g})$ & 97 & 97 & 97 & 97 & 97 \\
Farinha de arroz $(\mathrm{mL})$ & 200 & 150 & 100 & 50 & - \\
Farinha de casca de mandioca $(\mathrm{mL})$ & - & 50 & 100 & 150 & 200 \\
\hline
\end{tabular}

${ }^{\text {obs }}$ A quantidade de água utilizada em cada formulação foi diferente e proporcional a capacidade de absorção de água pela mistura de farinhas de arroz e de casca de mandioca, sendo suficiente para homogeneização e manutenção da mesma viscosidade entre as massas cruas.

Fonte: Elaboração dos autores.

A técnica de preparo padrão foi utilizada para obtenção da massa dos bolos e constituiu-se dos seguintes processos: pré-aquecimento do forno a $180{ }^{\circ} \mathrm{C}$; recobrimento da forma com margarina e FA; separação da gema da clara; bateção das claras até o ponto de neve; bateção da gema, açúcar e margarina por $5 \mathrm{~min}$ em batedeira planetária; mistura desta massa com as farinhas e o leite; bateção por mais $10 \mathrm{~min}$; mistura lenta e delicada da clara em neve e do fermento em pó a massa com auxílio de uma espátula; colocação da massa na forma e forneamento por aproximadamente $40 \mathrm{~min}$. Antes de desinformar aguardou-se o resfriamento até a temperatura ambiente.

\section{Características físicas das farinhas e bolos}

Nas farinhas de arroz e de casca de mandioca foram aferidos os parâmetros de cor (L*, a* e b*), por meio de colorímetro (Hunterlab, Colorquest II, Reston-Virgínia, USA) (HUNTERLAB, 1998).
A umidade das farinhas foi determinada em estufa simples (Fanem, 315-SE, São Paulo-SP, Brasil), enquanto que a dos bolos em estufa a vácuo (Tecnal, TE-395, Piracicaba-SP, Brasil), conforme os métodos $n^{\circ} 925.10$ e $n^{\circ} 926.12$ da AOAC (1997), respectivamente. $\mathrm{O} \mathrm{pH}$ das amostras foi aferido com potenciômetro digital (Hanna Instruments, HI9224, Singapore, China) e técnica descrita conforme método 017/IV do Instituto Adolf Lutz (INSTITUTO..., 2008). A determinação do $\mathrm{pH}$ permitiu observar se a farinha de casca de mandioca apresentou caráter mais similar ao polvilho doce ou azedo. Além das análises citadas, com exceção do $\mathrm{pH}$, os bolos prontos também foram avaliados em função do volume específico, por meio da determinação da massa em balança semianalítica e do volume pelo deslocamento de painço, conforme descrito por Camargo, Leonel e Mischan (2008). O índice de rendimento foi calculado pela razão entre a massa do bolo pronto e a somatória das massas dos ingredientes, com exceção da água (ORNELLAS, 2001). 


\section{Composição centesimal e valor energético}

As amostras de FA, de FCM e de todos os bolos prontos (tratamentos) foram avaliadas quanto ao conteúdo de proteínas pelo método micro Kjeldhal, com utilização do fator 5,95 para a FA e 6,25 para as demais amostras para conversão do nitrogênio em proteína; cinzas por incineração em mufla; fibra alimentar total, solúvel e insolúvel segundo método enzimático-gravimétrico; e lipídios em extrator Soxlet (Quimis, Q30826, Diadema-SP, Brasil), respectivamente de acordo com os métodos $\mathrm{n}^{\circ}$ 960.52, 923.03, 985.29 e 920.39C da AOAC (1997). Os carboidratos disponíveis foram calculados por diferença e o valor energético total foi estimado seguindo os valores de conversão de Atwater. A umidade e valor calórico foram expressos em base úmida e, a composição centesimal, em base seca.

\section{Pesquisa microbiológica}

As amostras de FA, de FCM e dos bolos foram avaliadas quanto à contagem de Bacilus cereus, coliformes a $45{ }^{\circ} \mathrm{C}$ e presença de Salmonella sp, segundo os itens $10 \mathrm{~A}, 10 \mathrm{E}$ e $10 \mathrm{~L}$ da RDC $n^{\circ}$ 12 da Agência Nacional de Vigilância Sanitária, respectivamente (BRASIL, 2001). Apesar de não ser exigido nesta legislação, as amostras também foram avaliadas em função da contagem de bolores e leveduras, coliformes totais e clostrídios sulfitos redutores, pelo fato de ser ou conter matéria-prima proveniente do solo e ter contato direto com a terra. As análises seguiram as técnicas descritas pela Food and Drug Administration dos EUA (FDA, 2002).

\section{Teste sensorial}

O projeto foi aprovado pelo Comitê em Ética e Pesquisa da Universidade Federal de Goiás (número 0161/10). A aceitação dos produtos quanto aos atributos aparência, textura, aroma e sabor foram avaliados usando escala hedônica de nove pontos, ancorada com termos verbais em todos os pontos, sendo os extremos correspondentes a "desgostei muitíssimo"para escore 1 e "gostei muitíssimo" para escore 9, e o meio, "nem gostei; nem desgostei" para escore 5). Verificou-se, também, a intenção de compra em escala de 5 pontos ancorada com termos verbais nos extremos, "certamente compraria" (escore 5) e "certamente não compraria" (escore 1), e no meio, "talvez comprasse / talvez não comprasse" (escore 3) (STONE; SIDEL, 1993).

Foram recrutados 40 provadores não treinados, adultos (19 a 30 anos) de ambos sexos, conforme interesse e disponibilidade em participar da pesquisa. $\mathrm{O}$ delineamento experimental utilizado foi de blocos completos ao acaso. Os bolos foram elaborados considerando todas as normas de boas práticas na fabricação de alimentos, no dia da análise, e armazenados em condições seguras para manter suas características sensoriais e higiênicosanitárias. Foram servidos de forma aleatorizada e avaliados em cabines individuais iluminadas com luz vermelha para os atributos de sabor, aroma e textura. A amostra foi servida em temperatura ambiente e em porções uniformes de aproximadamente 30 $\mathrm{g}$, apresentadas de forma monádica sequencial, em pratos plásticos descartáveis codificados com números de três dígitos. A aparência dos produtos foi avaliada independente das características de sabor, aroma e textura. A aparência global foi julgada com as amostras dispostas em pratos de fundo branco, codificados com números de três dígitos, iluminados por luz fluorescente (INSTITUTO..., 2008). Dois pontos de corte foram definidos previamente como limite mínimo para aceitação dos bolos: escore 6, que corresponde a "gostei levemente" na escala hedônica de nove pontos, e escore 3, que equivale a intenção de compra "talvez comprasse, talvez não comprasse".

\section{Análise estatística}

Os dados físicos, de composição centesimal e a aceitação sensorial dos bolos foram avaliados por análise de variância e as médias comparadas pelo teste de Tukey à $5 \%$ de probabilidade, utilizando- 
se o aplicativo Statistica 7 (Statsoft, Statistica 7, Thulsa, EUA).

\section{Resultados e Discussão}

Propriedades físicas e químicas das farinhas

Todos os parâmetros instrumentais de cor $\left(\mathrm{L}^{*}, \mathrm{a}^{*}\right.$ e $\left.\mathrm{b}^{*}\right)$, de $\mathrm{pH}$ e de umidade das amostras apresentaram diferenças (Tabela 2). A FA apresentou-se mais clara, com coloração menos avermelhada e amarelada, quando comparada a FCM. A coloração encontrada na FA foi diferente da observada por Garcia (2009) (provavelmente por diferenças genéticas, de solo e de clima de onde os grãos de arroz foram produzidos), onde os grãos de arroz das cultivares BRS Primavera e BRS Sertaneja, apresentaram-se menos claras ( $\mathrm{L}^{*}=$ 61,60 e 58,67), com maior intensidade de amarelo do que vermelho $\left(a^{*}=2,93\right.$ e 3,09 e $b^{*}=20,90$ e 19,98). Oliveira et al. (2005), avaliaram algumas características físicas e químicas de diferentes cultivares de mandioca e verificaram diferentes cores para a casca e entrecasca de mandioca, como branca, creme, amarelada, roxa e marrom. A cor de casca e da entrecasca influenciam a cor da FCM, o que a torna mais escura, avermelhada e amarelada que a FA, como pode ser observado neste trabalho. A cor escura da FCM torna-a mais aplicável na elaboração de produtos escuros, como aqueles que utilizam chocolate, café, caramelo, etc.

Tabela 2. Parâmetros de cor ( $\mathrm{L}^{*}, \mathrm{a}^{*}, \mathrm{~b}^{*}$ ), e valores de $\mathrm{pH}$, umidade (base úmida) e valor energético total (base úmida) e composição centesimal (base seca) das farinhas de arroz e de casca de mandioca.

\begin{tabular}{lcc}
\hline Variáveis físicas e químicas & Farinha de arroz & Farinha de casca de mandioca \\
\hline $\mathrm{L}^{*}$ & 79,3 & 57,5 \\
$\mathrm{a}^{*}$ & 0,4 & 7,5 \\
$\mathrm{~b}^{*}$ & 8,9 & 19,7 \\
$\mathrm{pH}$ & 6,2 & 4,8 \\
Umidade $^{1}$ & 11,5 & 12,8 \\
Cinzas $^{1}$ & 0,3 & 3,2 \\
Lipídeos totais $^{1}$ & 0,9 & 0,8 \\
Proteínas $^{1}$ & 7,9 & 4,0 \\
Carboidrato disponível $^{1}$ & 87,0 & 53,3 \\
Fibra total $^{1}$ & 3,9 & 38,7 \\
Fibra solúvel $^{1}$ & 1,8 & 5,1 \\
Fibra insolúvel $^{1}$ & 2,1 & 33,6 \\
Valor energético total $^{2}$ & 335,3 & 94,4 \\
\hline
\end{tabular}

${ }^{1}{\mathrm{~g} 100 \mathrm{~g}^{-1}}^{-1}$

${ }^{2} \mathrm{kcal} \mathrm{g}^{-1}$

Obs.: Análises foram realizadas em três repetições, em triplicata.

Fonte: Elaboração dos autores.

$\mathrm{O}$ pH da FA foi maior que o da FCM (Tabela 2). Augusto-Ruiz et al. (2003) encontraram, em grãos de arroz polidos, pH entre 6,0 e 6,4. Neste estudo a FA, constituída pelos grãos polidos que sofreram moagem, apresentou $\mathrm{pH}$ dentro da faixa da literatura citada. A FCM apresentou valor de $\mathrm{pH}$ próximo ao encontrado por Vilhauva et al. (2012),
$\mathrm{pH}$ de 4,28 , e semelhante ao $\mathrm{pH}$ do polvilho azedo $(4,18)$ (PEREIRA et al., 1999).

A umidade da FA foi menor que a da FCM (Tabela 2). A casca apresenta geralmente 75 g.100 $\mathrm{g}^{-1}$ de umidade (CEREDA, 1996), enquanto o arroz é colhido com umidade entre 15 e 30 g. $100 \mathrm{~g}^{-1}$, contudo ambas as farinhas devem ser armazenadas 
após secagem com umidade inferior a 14 g.100 $\mathrm{g}^{-1}$, obedecendo, assim, os padrões de qualidade exigidos para farinhas pela legislação brasileira (BRASIL, 2005).

A FCM apresentou teores superiores de cinzas, fibra alimentar total, solúvel e insolúvel e inferiores de proteínas e carboidratos disponíveis, além do valor energético total em relação a FA. Dors, Pinto e Badiale-Furlong (2009) encontraram em grãos de arroz polidos, teores de cinzas $\left[0,22 \mathrm{~g} .100 \mathrm{~g}^{-1}\right]$, proteínas $\left[8,3 . \mathrm{g} 100 \mathrm{~g}^{-1}\right]$, carboidratos disponíveis [85 g.100 g $\mathrm{g}^{-1}$ ] e fibras alimentares totais [4,2 g.100 $\mathrm{g}^{-1}$ ] semelhantes aos da FA obtidos neste trabalho. Vilhalva et al. (2012) avaliou a composição da mistura das duas frações da casca e encontrou 31,85 g.100 g $\mathrm{g}^{-1}$ de carboidratos disponíveis; $3,48 \mathrm{~g} .100 \mathrm{~g}^{-1}$ de cinzas; 4,04 g.100 g $\mathrm{g}^{-1}$ de proteína; 50,49 g.100 g-1 de fibra alimentar total; 48,66 g.100 $\mathrm{g}^{-1}$ de fibra alimentar solúvel; 1,83 g. $100 \mathrm{~g}^{-1}$ de fibra alimentar insolúvel e 0,54 g. $100 \mathrm{~g}^{-1}$ de lipídeos. Neste trabalho, obtiveramse teores maiores de carboidratos disponíveis, fibra alimentar insolúvel e lipídeos, menores de cinzas, fibra alimentar total, fibra alimentar solúvel e semelhante de proteína dos obtidos pela referida autora. Cereda (1994) relatou teores de fibras totais na fração casca marrom de $41 \mathrm{~g} .100 \mathrm{~g}^{-1}$, indo de encontro ao determinado neste estudo.

A Portaria $\mathrm{n}^{0} 27$ da Agência Nacional de Vigilância Sanitária de 1998 classifica os alimentos sólidos de acordo com o teor de fibras presente em $100 \mathrm{~g}$ de produto como fonte (mínimo de $3 \mathrm{~g} .100$ $\left.\mathrm{g}^{-1}\right)$ e alto teor ( 6 g.100 $\left.\mathrm{g}^{-1}\right)$ (BRASIL, 1998). Assim, a FA pode ser classificada como produto fonte de fibras, enquanto a FCM como produto de alto teor de fibras. O teor de fibra alimentar solúvel da FCM foi quase três vezes maior que o da FA, enquanto o de fibra alimentar insolúvel foi dezesseis vezes maior. Portanto, a FCM pode ser utilizada para enriquecer em fibras solúveis e insolúveis diversos tipos de alimentos, como os panificados, lácteos, cárneos e outros.
Propriedades físicas, composição centesimal e valor energético dos bolos

O volume específico dos bolos não diferiu entre os tratamentos (Tabela 3). Uma vez que o volume específico é extremamente importante para atributos como aparência, textura, refletindo na aceitabilidade dos produtos panificados, a não alteração desse parâmetro é uma informação importante para mostrar a viabiliadade de utilização da FCM como substituinte da FA em formulação de bolo sem glúten.

O volume específico mostra claramente a relação entre o teor de sólidos e a fração de ar existente na massa assada. Pães ou bolos com volumes específicos baixos apresentam aspecto desagradável ao consumidor e estão associados com alto teor de umidade, falhas no batimento e na cocção, pouca aeração, difícil mastigação, sabor impróprio e baixa conservação (ESTELLER; LANNES, 2005). Schamne, Dutcosky e Demiate (2010) desenvolveram bolos e pães isentos de glúten, utilizando FA, amido de milho e amido de mandioca. Os volumes específicos observados pelos autores nas formulações com FA e amido de mandioca foram menores aos obtidos neste estudo.

$\mathrm{O}$ valor da luminosidade e da coordenada $\mathrm{b}^{*}$ do miolo diferiram entre os tratamentos (Tabela 3), em função das características de cor da FCM, que se mostrou muito mais escura que a FA (Tabela 2). A adição de mais que $25 \%$ de FCM resultou em bolos com coloração chocolate, conforme relatado pelo provadores.. 
Tabela 3. Caracterização de bolos com diferentes percentuais de substituição de farinha de arroz por farinha de casca de mandioca, em $(\mathrm{v} / \mathrm{v})^{*}$.

\begin{tabular}{|c|c|c|c|c|c|}
\hline \multirow{2}{*}{ Característica } & \multicolumn{5}{|c|}{$\begin{array}{c}\text { Tratamento } \\
\text { (Nível de substituição da farinha de trigo por farinha da casca de mandioca) }\end{array}$} \\
\hline & $\mathrm{B} 1(0 \%)$ & B2 $(25 \%)$ & B3 $(50 \%)$ & B4 $(75 \%)$ & B5 (100\% \\
\hline Volume específico $^{1}$ & $1,9^{\mathrm{a}}$ & $1,9^{\mathrm{a}}$ & $1,9^{\mathrm{a}}$ & $1,6^{\mathrm{a}}$ & $1,8^{\mathrm{a}}$ \\
\hline $\mathrm{L}^{*}$ miolo & $57,5^{\mathrm{a}}$ & $25,4^{\mathrm{b}}$ & $13,2^{\mathrm{e}}$ & $22,1^{\mathrm{c}}$ & $22,9^{\mathrm{d}}$ \\
\hline a*miolo & $-0,4^{\mathrm{d}}$ & $7,9^{\mathrm{a}}$ & $5,8^{\mathrm{b}}$ & $5,0^{\mathrm{c}}$ & $8,2^{\mathrm{a}}$ \\
\hline $\mathrm{b}^{*}$ miolo & $15,7^{\mathrm{a}}$ & $8,6^{c}$ & $3,3^{\mathrm{e}}$ & $10,1^{\mathrm{b}}$ & $7,7^{\mathrm{d}}$ \\
\hline Umidade $^{2}$ & $29,6^{\mathrm{d}}$ & $28,3^{\mathrm{e}}$ & $34,6^{c}$ & $36,0^{\mathrm{b}}$ & $41,8^{\mathrm{a}}$ \\
\hline Índice de rendimento & 0,72 & 0,80 & 0,80 & 0,84 & 0,84 \\
\hline Cinzas $^{2}$ & $3,1^{\mathrm{e}}$ & $3,8^{\mathrm{c}}$ & $3,5^{\mathrm{d}}$ & $4,3^{\mathrm{b}}$ & $4,8^{\mathrm{a}}$ \\
\hline Lipídeos $^{2}$ & $8,6^{\mathrm{d}}$ & $11,6^{\mathrm{c}}$ & $11,3^{\mathrm{c}}$ & $14,9^{\mathrm{b}}$ & $16,7^{\mathrm{a}}$ \\
\hline Proteína ${ }^{2}$ & $8,5^{\mathrm{a}}$ & $8,4^{\mathrm{a}}$ & $8,6^{\mathrm{a}}$ & $8,3^{\mathrm{a}}$ & $7,3^{\mathrm{b}}$ \\
\hline Carboidrato disponível $^{2}$ & $75,7^{\mathrm{a}}$ & $67,3^{\mathrm{b}}$ & $60,9^{c}$ & $58,1^{\mathrm{d}}$ & $51,9^{\mathrm{e}}$ \\
\hline Fibra alimentar total ${ }^{2}$ & $4,1^{\mathrm{d}}$ & $8,9^{\mathrm{c}}$ & $15,7^{\mathrm{b}}$ & $14,4^{b}$ & $19,3^{\mathrm{a}}$ \\
\hline Fibra alimentar solúvel $^{2}$ & $0,6^{\mathrm{b}}$ & $2,7^{\mathrm{ac}}$ & $3,9^{\mathrm{a}}$ & $1,2^{\mathrm{bc}}$ & $2,0^{\mathrm{c}}$ \\
\hline Fibra alimentar insolúvel ${ }^{2}$ & $3,5^{\mathrm{d}}$ & $6,2^{\mathrm{c}}$ & $11,8^{\mathrm{b}}$ & $13,2^{\mathrm{b}}$ & $17,3^{\mathrm{a}}$ \\
\hline Valor energético total ${ }^{3}$ & $281,7^{\mathrm{a}}$ & $273,9^{\mathrm{b}}$ & $217,6^{\mathrm{d}}$ & $221,86^{\mathrm{c}}$ & $184,76^{\mathrm{e}}$ \\
\hline
\end{tabular}

*Valores com letras iguais na mesma linha não diferiram significativamente ao nível de 5\%. Umidade e valor energético expressos em base úmida e, composição centesimal, em base seca.

${ }^{1} \mathrm{~mL} \mathrm{~g}^{-1}$

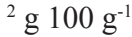

${ }^{3}$ Kcal g-1

Obs.: Análises foram realizadas em três repetições, em triplicata.

Fonte: Elaboração dos autores.

Em relação à coordenada $\mathrm{a}^{*}$, os miolos dos bolos B2 e B5 não diferiram entre si, mas diferiram $(\mathrm{p} \leq 0,05)$ dos demais tratamentos. B1 ficou próximo a zero. Com o aumento dos níveis de substituição da FA por FCM, os miolos dos bolos tornaram-se mais avermelhados. O bolo com miolo mais amarelado foi aquele sem substituição da FA pela FCM, seguido pelo bolo com $25 \%$ de substituição (Tabela 3). Isso provavelmente ocorre pelo fato das farinhas obtidas de resíduos, geralmente, serem constituídas por certa quantidade de cascas ou passarem por processos térmicos, que provocam o escurecimento das farinhas obtidas e, consequentemente, dos produtos formulados com as mesmas (SOARES JÚNIOR et al., 2009).

Todos os bolos diferiram em relação ao teor de umidade, apresentando tendência de aumento com o nível de substituição da FA por FCM (Tabela 3), fato relacionado com a elevação do teor de fibras. A absorção de água é maior em produtos com maior quantidade de fibras, principalmente as insolúveis, pois estas apresentam maior poder de retenção de água. Esta característica pode conferir à massa menor estabilidade e conservação durante armazenamento (TORBICA; HADNADEV; DAPCEVIC, 2010).

$\mathrm{O}$ índice de rendimento apresentou tendência de aumento com a maior substituição da FA pela FCM nos bolos (Tabela 3), sendo esta mudança atribuída, possivelmente, à diferença de umidade das farinhas, que ocasionou aumento da massa final dos bolos com a maior substituição de FA por FCM. Silva et al. (2010) relataram o fato das fibras absorverem maior quantidade de água, pode levar a aumento do rendimento em formulações de panificados, contudo, também, questionaram a capacidade reduzida de conferirem algumas características tecnológicas aos produtos como, elasticidade, coesividade, conformação e firmeza em água quente. 
As cinzas, os lipídeos e as fibras alimentares total e insolúvel apresentaram tendência de aumento nos bolos com a substituição de FA pela FCM, já os carboidratos disponíveis e o valor energético total de diminuir nos bolos com o aumento da substituição da FA pela FCM (Tabela 3). Em relação aos teores de cinzas, carboidratos disponíveis e valor energético total, todos os bolos diferiram entre si. Para os lipídeos, o B2 e B3 não apresentam diferença, mas foram diferentes dos demais bolos. Para o teor de proteína, apenas o B5 foi menor e diferiu dos demais tratamentos. Para fibra alimentar total, apenas B3 e B4 não diferiram entre si, mas diferiram dos demais tratamentos.

A fibra alimentar solúvel aumentou em relação ao nível de substituição da FA pela FCM até 50\% (Tabela 3). Todos os bolos com FCM apresentaram teor de fibras superior à obtida pelo bolo sem FCM. Esta tendência era esperada, uma vez que a FCM apresenta teores muito superiores de fibras alimentares que a FA, desta forma seus produtos também devem refletir esta composição. Assim, o bolo B1 ( $0 \%$ de substituição de FA por FCM) pode ser considerado fonte de fibras e os demais bolos como alimentos ricos em fibras.

Segundo o Institute of Medicine (2005) o consumo de uma porção de $50 \mathrm{~g}$ do bolo com substituição intermediária $(50 \%)$ da FA pela FCM deste bolo representaria $23,42 \%$ das necessidades diárias de carboidratos disponíveis para homens e mulheres adultos, 7,69\% e 9,35\% das proteínas para homens e mulheres respectivamente e $20,66 \%$ de fibras alimentares totais para homens e $31,4 \%$ para mulheres.

\section{Perfil microbiológico das farinhas e bolos}

As amostras de FA, FCM e dos bolos não apresentaram contaminação com os microrganismos Bacilus cereus, coliformes totais e a $45{ }^{\circ} \mathrm{C}$, Salmonella sp, bolores e leveduras e clostrídios sulfitos redutores. Isso pode ser atribuído ao processo de sanitização e secagem ao qual a FCM foi submetida, ao forneamento dos bolos, à adoção de boas práticas de fabricação e à água utilizada na lavagem da mandioca. Pois, supõem-se que a água vegetal (extraída do interior da mandioca) seja um agente anti-microbiano, devido sua acidez e presença de ácido cianídrico.

\section{Aceitabilidade dos bolos}

Todos os bolos foram considerados aceitos (escore acima de 6) (Tabela 4), sendo que a maioria dos obteve escores entre 6 e 7, entre "gostei levemente" e "gostei moderadamente", para todos os atributos. Não houve diferenças em relação à aceitação para a aparência, aroma, textura e sabor, indicando a possibilidade de se empregar diferentes níveis de FA por FCM.

Tabela 4. Aceitação média quanto aos atributos de aparência, aroma, textura e sabor obtido pelos bolos com diferentes níveis de substituição de farinha de arroz por farinha de casca de mandioca em v/v.

\section{Tratamento}

\section{Atributo}

(Nível de substituição da farinha de trigo por farinha da casca de mandioca)

\begin{tabular}{lccccc} 
& B1 $(0 \%)$ & B2 $(25 \%)$ & B3 $(50 \%)$ & B4 $(75 \%)$ & B5 $(100 \%)$ \\
\hline Aparência $^{1}$ & $7,1^{\mathrm{a}}$ & $6,7^{\mathrm{a}}$ & $7,1^{\mathrm{a}}$ & $6,8^{\mathrm{a}}$ & $7,0^{\mathrm{a}}$ \\
Aroma & $7,0^{\mathrm{a}}$ & $6,4^{\mathrm{a}}$ & $6,8^{\mathrm{a}}$ & $6,8^{\mathrm{a}}$ & $6,9^{\mathrm{a}}$ \\
Textura & $6,3^{\mathrm{a}}$ & $7,0^{\mathrm{a}}$ & $6,6^{\mathrm{a}}$ & $6,7^{\mathrm{a}}$ & $6,8^{\mathrm{a}}$ \\
Sabor & $6,8^{\mathrm{a}}$ & $6,7^{\mathrm{a}}$ & $6,6^{\mathrm{a}}$ & $6,6^{\mathrm{a}}$ & $6,3^{\mathrm{a}}$ \\
\hline
\end{tabular}

${ }^{1}$ Valores com letras iguais na mesma linha não diferiram significativamente ao nível de $5 \%$.

Obs.: Teste realizado com 40 provadores.

Fonte: Elaboração dos autores. 
Quanto a intenção de compra, para os produtos B1, B2, B3 e B4 muitos dos consumidores (34\%, $48 \%, 44 \%$ e $35 \%$, respectivamente) indicaram que "talvez comprasse / talvez não comprasse" (escore 3), atingindo assim o ponto de corte definido neste estudo. B5 destacou-se pela intenção de compra, já que a opção mais escolhida (40\% dos consumidores) foi a de "possivelmente compraria" (escore 4), indicando inclusive a possibilidade de uma substituição total.

\section{Conclusões}

Os resultados obtidos neste estudo demonstram a possibilidade de utilização da FCM como substituinte da FA em formulações de bolos sem glúten, uma vez que estes apresentaram resultados satisfatórios em relação às características físicas, valor nutricional, segurança microbiológica e aceitação sensorial. Desta forma, pode-se considerar que todas as misturas para bolos teriam potencial para aceitação e compra no mercado, inclusive a formulação com $100 \%$ de substituição de farinha de arroz por farinha de casca de mandioca.

\section{Agradecimentos}

A Capes pela bolsa de mestrado e a Capes e Fapeg pelo apoio financeiro.

\section{Referências}

ASSOCIATION OF OFFICIAL ANALYTICAL CHEMISTS - AOAC. Official methods of analysis of AOAC International. 16. ed. Gaitherburg: AOAC International, 1997.

AUGUSTO-RUIZ, W.; BONATO, S. R.; ARRIECHE, L. S.; ALVES, F. V. Caracterização da farinha prégelatinizada de arroz integral produzida a partir de grãos quebrados. Vetor, Rio Grande, v. 13, p. 25-46, 2003.

BRASIL. Agência Nacional de Vigilância Sanitária - ANVISA. Portaria $n^{\circ} 27$, de 13 de janeiro de 1998. Aprova o regulamento técnico referente à informação nutricional complementar. Brasília: ANVISA, 1998. Disponível em: <http://www.anvisa.gov.br/e-legis/>. Acesso em: 12 jan. 2013.
Resolução RDC $n^{\circ} 12$, de 02 de

janeiro de 2001. Regulamento técnico sobre padrões microbiológicos para alimentos. Disponível em: $<\mathrm{http}: / /$ www.e-legis.bvs.br>. Acesso em: 21 jan. 2013.

Resolução RDC $n^{o} .263$, de 22 de setembro de 2005. Regulamento técnico para produtos de cereais, amidos, farinhas e farelos. Disponível em: $<$ http://www.e-legis.bvs.br>. Acesso em: 21 jan. 2013.

BRITO, A. C. W. Desenvolvimento de um purê misto de frutas pronto para consumo. 2008. Dissertação (Mestrado em Tecnologia de Alimentos) - Setor de Tecnologia. Universidade Federal do Paraná, Curitiba.

CAGNON, J. R.; CEREDA, M. P.; PANTAROTTO, S. Glicosídeos cianogênicos da cassava: biossíntese, distribuição, detoxificação e métodos de dosagem. In: CEREDA, M. P. (Coord.). Agricultura: tuberosas Amiláceas Latino Americanas. São Paulo: Fundação Cargill, 2002. v. 2, cap. 5, p. 83-99. (Série Tuberosas Amiláceas Latino Americanas).

CAMARGO, K. F.; LEONEL, M.; MISCHAN, M. M. Produção de biscoitos extrusados de polvilho azedo com fibras: efeito de parâmetros operacionais sobre as propriedades físicas. Ciência e Tecnologia de Alimentos, Campinas, v. 28, n. 3, p. 586-591, 2008.

CARVALHO, W. T.; REIS, R. C.; VELASCO, P.; SOARES JÚNIOR, M. S.; BASSINELLO, P. Z; CALIARI, M. Características físico-químicas de extratos de arroz integral, quirera de arroz e soja. Pesquisa Agropecuária Tropical, Goiânia, v. 41, n. 3, p. 421-429, 2011.

CEREDA, M. P. Agricultura: tuberosas amiláceas latinoamericanas. São Paulo: Fundação Cargill, 2002. v. 2.

Caracterização dos resíduos da industrialização da mandioca. In: _. Resíduos da industrialização da mandioca no Brasil. São Paulo: Paulicéia, 1994. p. 11-50.

. Caracterização, usos e tratamentos de resíduos da industrialização da mandioca. Botucatu: Centro de Raízes Tropicais/Universidade Estadual Paulista, 1996. $56 \mathrm{p}$.

DORS, G. C.; PINTO, R. H.; BADIALE-FURLONG, E. Influência das condições de parboilização na composição química do arroz. Ciência e Tecnologia de Alimentos, Campinas, v. 29, n. 1, p. 219-224, 2009.

EMPRESA BRASILEIRA DE PESQUISA AGROPECUÁRIA - EMBRAPA. Embrapa mandioca e fruticultura. Importância da mandioca. 2009. Disponível em: $<$ http://sistemasdeproducao.cnptia.embrapa. $\mathrm{br} /$ FontesHTML/Mandioca/mandioca cerrados/ importancia.htm>. Acesso em: 22 jan. 2013. 
ESTELLER, M. S.; LANNES, S. C. S. Parâmetros complementares para fixação de identidade e qualidade de produtos panificados. Ciência e Tecnologia de Alimentos, Campinas, v. 25, n. 4, p. 802-806, 2005.

FOOD AND DRUG ADMINISTRATION - FDA. Bacteriological analytical manual. 2002. Disponível em: $<\mathrm{http} / /$ :www.cfsan.fda.gov/ eban/ban-4html $>$.Acesso em: 22 jan. 2013.

GARCIA, D. M. Efeito da época de colheita na qualidade do arroz de terras altas submetido à parboilização. 2009. Dissertação (Mestrado em Ciência e Tecnologia de Alimentos) - Escola de Agronomia e Engenharia de Alimentos. Universidade Federal de Goiás, Goiânia.

HUNTERLAB. User's manual with universal software versions 3.5. Reston, Hunterlab, 1998. 428 p.

INSTITUTO ADOLFO LUTZ - IAL. Métodos físicoquímicos para análise de alimentos. 4. ed. São Paulo: Instituto Adolfo Lutz, 2008. 1002 p.

INSTITUTE OF MEDICINE - IOM. Dietary reference intakes for energy, carbohydrate, fiber, fat, fatty acids, cholesterol, protein and amino acids. Washington: National Academy Press, 2005. 1331 p.

OLIVEIRA, M. A.; LEONEL, M.; CABELLO, C.; CEREDA, M. P.; JANES, D. A. Metodologia para avaliação do tempo de cozimento e características tecnológicas associadas em diferentes cultivares de mandioca. Ciência e Agrotecnologia, Lavras, v. 29, n. 1, p. 126-133, 2005.

ORNELLAS, L. H. Técnica dietética: seleção e preparo de alimentos. 7. ed. São Paulo: Atheneu, 2001. 330 p.

PEREIRA, J.; CIACCO, C. F.; VILELA, E. R.; TEIXEIRA, A. L. de S. Féculas fermentadas na fabricação de biscoitos: estudo de fontes alternativas. Ciência e Tecnologia de Alimentos, Campinas, v. 19, n. 2, p. 287-293, 1999.

SCHAMNE, C.; DUTCOSKY, S. D.; DEMIATE, I. M. Obtention and characterization of gluten-free baked products. Ciência e Tecnologia de Alimentos, Campinas, v. 30, n. 3, p. 741-750, 2010.

SDEPANIAN, V. L.; MORAIS, M. B.; FAGUNDESNETO, U. Doença celíaca: avaliação da obediência à dieta isenta de glúten e do conhecimento da doença pelos pacientes cadastrados na Associação dos Celíacos do Brasil (ACELBRA). Arquivos de Gastroenterologia, São Paulo, v. 38, n. 1, p. 232-239, 2001.

SILVA, L. M. R.; ABREU, D. A. A.; SOARES, D. J.; PONTES, D. F.; CONSTANT, P. B. L. S. Processamento de bolo com farinha de quinoa (Chenopodium quinoa
Willd): estudo de aceitabilidade. Revista Brasileira de Produtos Agroindustriais, Campina Grande, v. 12, n. 2, p. 125-132, 2010.

SOARES JÚNIOR, M. S.; BASSINELLO, P. Z.; CALIARI, M., GEBIN, P. F. C.; JUNQUEIRA, T. L.; GOMES, V. A.; LACERDA, B. C. L. D. Qualidade de pães com farelo de arroz torrado. Ciência e Tecnologia de Alimentos, Campinas, v. 29, n. 3, p. 636-641, 2009.

SOARES JÚNIOR, M. S.; BASSINELLO, P. Z.; CALIARI, M.; VELASCO, P.; REIS, R. C.; CARVALHO, W.T. Bebidas saborizadas obtidas de extratos de quirera de arroz, arroz integral e de soja. Ciência e Agrotecnologia, Lavras, v. 34, n. 2, p. 407-413, 2010.

SOARES JÚNIOR, M. S.; SANTOS, T. P. B.; PEREIRA, G. F.; MINAFRA, C. S.; CALIARI, M.; SILVA, F. A. Desenvolvimento de salgadinhos extrusados a partir de fragmentos de arroz e de feijão. Semina: Ciências Agrárias, Londrina, v. 32, n. 1, p. 189-198, 2011.

STONE, H.; SIDEL, J. Sensory evaluation practices. New York: Academic Press, 1993. 3380 p.

TAVARES, J. S.; SOARES JÚNIOR, M. S.; BECKER, F. S.; EIFERT, E. C. Mudanças funcionais de farinha de arroz torrada com micro-ondas em função do teor de umidade e do tempo de processamento. Ciência Rural, Santa Maria, v. 42, n. 6, p. 1102-1109, 2012.

TORBICA, A.; HADNACEV, M.; DAPCEVIC, T. Rheological, textural and sensory properties of glutenfree bread formulations based on rice and buckwheat flour. Food Hydrocolloids, Bocca Raton, v. 24, n. 6-7, p. 626-632, 2010.

UGWU, C. U.; TOKIWA, Y.; AOYAGI, H. Utilization of broken rice for the production of poly (3-hydroxybutyrate). Journal of Polymers and the Environment, New York, v. 20, n. 3, p. 254-257, 2012.

VILHALVA, D. A. A.; SOARES JÚNIOR, M. S.; CALIARI, M.; SILVA, F. A. Secagem convencional de casca de mandioca proveniente de resíduos de indústria de amido. Pesquisa Agropecuária Tropical, Goiânia, v. 42, n. 3, p. 331-339, 2012.

VILHALVA, D. A. A.; SOARES JÚNIOR, M. S.; MOURA, C. M. A.; CALIARI, M. SOUZA, T. A. C.; SILVA, F. A. Aproveitamento da farinha de casca de mandioca na elaboração de pão de forma. Revista do Instituto Adolfo Lutz, São Paulo, v. 70, n. 4, p. 514-521, 2011.

VILPOUX, O. Fécula de mandioca no Brasil. Botucatu: Raízes, 2003. 14 p. 
